\title{
Institutional delivery service utilization and associated factors in Banja District, Awie Zone, Amhara Regional Sate, Ethiopia
}

\author{
Alemaw Wolelie ${ }^{1}$, Mekonnen Aychiluhm², Worku Awoke ${ }^{3 *}$ \\ ${ }^{1}$ Amhara Regional State Health Bureau, Bahir Dar, Ethiopia \\ ${ }^{2}$ GAMBY College of Medicine and Health Sciences, Bahir Dar, Ethiopia \\ ${ }^{3}$ College of Medicine and Health Sciences, Bahir Dar University, Bahir Dar, Ethiopia \\ Email: Workuawo@yahoo.com
}

Received 3 December 2013; revised 3 January 2014; accepted 10 January 2014

Copyright (C 2014 Alemaw Wolelie et al. This is an open access article distributed under the Creative Commons Attribution License, which permits unrestricted use, distribution, and reproduction in any medium, provided the original work is properly cited. In accordance of the Creative Commons Attribution License all Copyrights (C) 2014 are reserved for SCIRP and the owner of the intellectual property Alemaw Wolelie et al. All Copyright @ 2014 are guarded by law and by SCIRP as a guardian.

\section{ABSTRACT}

Introduction: Many women lose their lives in the process of giving life. Maternal mortality remains high in the developing world. This study was conducted to assess institutional delivery service utilization and associated factors in Banja District, Amhara region, Ethiopia, 2013. Methods: A community-based cross-sectional study was conducted among mothers who gave birth in the last two years prior to the study in Banja District from June to July 2013. Multistage sampling technique was used to select the total of 394 study participants. Data were collected by means of a pretested standardized questionnaire. Analysis was carried out by using SPSS version 16. Crude and adjusted odds ratio with $95 \%$ confidence interval was calculated by using binary logistic regression. p-value less than 0.05 was considered as statistically significant. Results: The study indicated that only $15.7 \%$ of the respondents delivered in health institution. Age of mothers 15 - 24 years, educational status of the mothers with secondary and above, the existence of educated family members, mothers with previous experience with institutional delivery and mothers' Knowledge on the danger signs of labor were significantly associated with institutional delivery service utilization at p-value less than 0.05. Conclusions: Institutional delivery service utilization in the study

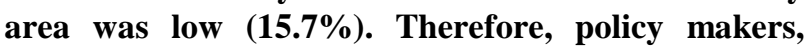
health planers and programmers should recognize determinants of institutional delivery service utilization. More efforts should be given to educate mothers and families. Previous experience sharing and know-

\footnotetext{
${ }^{*}$ Corresponding author.
}

ledge transfer will be crucial to bring expected institutional delivery utilization.

\section{KEYWORDS}

Institutional Delivery; Ethiopia

\section{INTRODUCTION}

The health of mothers and children is central to global and national concerns, and improvements in maternal and child survival are the two important Millennium Development goals [1].

Maternal mortality remains high in the developing world. In the developing world, the risk of death from complications relating to pregnancy and childbirth over the course of a woman's lifetime is one in 76, compared with one in 8000 in the industrialized world [2].

Globally, there are estimated 287,000 maternal deaths in 2010. Developing countries account for $99 \%(284,000)$ of the global maternal deaths. Out of this Ethiopia, accounts 9000 of the global maternal deaths are reported in 2010 [3].

Reducing maternal mortality is one of the Millennium Development Goals (MDGs) targeted reduce maternal mortality rate by an average of $5.5 \%$ every year over the period 1990-2015 [4]; however at the global level, decreased by less than 1\% per year between 1990 and 2005 which is far below 5.5\% to reach the target [5].

In Ethiopia, maternal mortality in year 2011 was estimated to be 676 per 100,000 live births which were not significantly different from year 2005 [6,7]. This study was conducted to assess institutional delivery and asso- 
ciated factors among mothers who gave birth in the last two years in Banja District, Amhara Region, Ethiopia, 2013.

\section{METHODS}

\subsection{Study Design}

A community-based cross sectional study design was conducted among mothers who gave birth in the preceding two years prior to data collection.

\subsection{Study Area}

This study was conducted in Banja District which is located at a distant of 447 kilometers in the northwest direction from Addis Ababa (capital city of Ethiopia) and at a distant of $118 \mathrm{~km}$ Bahir Dar City (capital city of Amhra Regional State). The total population was estimated to be 99,742 . Of which $20.9 \%$ are women in the reproductive age groups (15 - 49) years. The district is structured into 26 Kebeles (the smallest administrative level). There are one private clinic, 4 health centers, and 25 health posts. Health centers and health posts inter linked by referral system [8].

\subsection{Sampling Method and Sample Size Determination}

The sample size was determined by using single population proportion formula by considering the following assumption: Prevalence of institutional delivery a study done elsewhere $(\mathrm{P}=14 \%)$, level of significance $(\alpha=$ $5 \%$ ), 5\% marginal error , designing effect of 2 and by adding $10 \%$ of non response rate which gives the final sample size to be 394. Then, multi-stage sampling technique was used to select the study subjects. In the first stage, five kebeles were selected randomly using list of kebeles as sampling. In the second stage, mothers who gave birth the past two year were selected using systematic sampling method.

\subsection{Data Collection Instruments and Procedure}

A pretested standard questionnaire was prepared in English language. The English version was translated to the local Amharic language. Four diploma female nurses and two supervisors were as data collectors and supervisors respectively.

The data collectors and supervisors were trained for two days mainly on the objectives of the study, understanding of the questionnaire and basic techniques of interviewing and how to handle ethical issues. Participation in the study was voluntary base and confidentiality of the information was assured. Data were collected after getting informed consent from the selected mothers.

\subsection{Data Analysis}

Analysis was done using SPSS version 16 soft ware. Univariate analyses were done using frequency, percentage, tables and charts. Associations between dependent and independent variables were assessed using logistic regression. Multivariate analysis was done using backward stepwise logistic regression to assess individual effect of variables on institutional delivery services utilizations. Crude and adjusted odds ratio with 95\% confidence interval was calculated using binary logistic regression; p-value less than 0.05 was considered as statistically significant

\subsection{Ethical Considerations}

Ethical clearance was sought from GAMBY College of Medical Sciences. Formal letter of permission was obtained from Amhara Regional Health Bureau of Research and Technology transfer core process and on Banja District health office. Moreover; all selected participants were communicated about the objective of study in order to obtain their verbal consent before administering questionnaires. Participants were also informed their full right to withdraw or refuse to participate in the study. Data were collected after getting informed consent from the selected mothers.

\section{RESULTS}

\subsection{Socio-Demographic Characteristics of the Respondents}

A total of 394 mothers who gave birth in the last two years before the data collection time were invited to participate in this study; all of them were participated. The age group, $24.4 \%$ of the respondents were in the age group of 25 - 29 years, $25.1 \%$ were in the age group of 30 - 34 years and $26.1 \%$ ) of the respondents were 35-39 years. Majority 377 (95.7\%) of the respondents were married. Regarding Ethnic groups, 329 (83.5\%) and 65 (16.5\%) respondents were Agew and Amhara respectively. The Majority 363 (92.1\%) of the respondents was house wives and 357 (90.5\%) of husband's occupational status were farmers.

The income revealed that the poorest/lowest, second, middle, fourth and highest quintile (from the respondent's level) accounted for 18.5\%, 21.8\%, 23.1\%, 16.8\% and $19.8 \%$ respectively. Concerning walking distance from nearby health institution, 322 (81.7\%) were lived in less than one hour of walking distance and 72 (18.3\%) were more than one hours. the mean numbers of people living in a household were (Table 1).

\subsection{Maternal Factors}

Three hundred fifty, $89.3 \%$ of the mothers, the first 
Table 1. Socio-demographic characteristics of mothers in Banja District, Awi Zone, North West Ethiopia, October, 2013 (N = 394).

\begin{tabular}{|c|c|}
\hline Socio demographic Variables & $\mathbf{N}(\%)$ \\
\hline \multicolumn{2}{|l|}{ Age of mother } \\
\hline $15-19$ & $10(2.5)$ \\
\hline $20-24$ & $59(15)$ \\
\hline $25-29$ & $96(24.4)$ \\
\hline $30-34$ & $103(26.1)$ \\
\hline $35-39$ & $99(25.1)$ \\
\hline $40+$ & $27(6.9)$ \\
\hline \multicolumn{2}{|l|}{ Marital Status of mother } \\
\hline Married & $377(95.7)$ \\
\hline Single/Divorced/widowed/ & $17(18.3)$ \\
\hline \multicolumn{2}{|l|}{ Educational Status of mother } \\
\hline Unable to read \& write & $(79.2)$ \\
\hline Able to read \& write & $30(7.6)$ \\
\hline Elementary education (Grade 1 - 8) & $40(10.2)$ \\
\hline High school and above (Grade 9 and above) & $12(3)$ \\
\hline \multicolumn{2}{|l|}{ Ethnicity of mother } \\
\hline Agew & $329(83.5)$ \\
\hline Amhara & $65(16.5)$ \\
\hline \multicolumn{2}{|l|}{ Income/Month } \\
\hline$\leq 100.00 \mathrm{ETB}^{*}$ & $73(18.5)$ \\
\hline $100.00-170.00$ ETB & $86(21.8)$ \\
\hline 171.00 - 300.00 ЕТВ & $91(23.1)$ \\
\hline $301-566.00$ ЕTВ & $66(16.8)$ \\
\hline Above566.00 ETB & $78(19.8)$ \\
\hline \multicolumn{2}{|l|}{ Family size } \\
\hline$<6$ & $222(56.3)$ \\
\hline$\geq 6$ & $172(43.7)$ \\
\hline \multicolumn{2}{|l|}{ Educated Family in the household } \\
\hline Less than half of the family member & $255(64.7)$ \\
\hline Half \&more of the family member & 139 (35.3) \\
\hline \multicolumn{2}{|l|}{ Educational Status of husband (n = 394 ) } \\
\hline Unable to read \& write & $151(38.3)$ \\
\hline Able to read \& write & $155(39.3)$ \\
\hline Elementary education (Grade 1 - 8) & $59(15)$ \\
\hline High school and above (Grade 9 and above) & $29(7.4)$ \\
\hline \multicolumn{2}{|l|}{ Availability of Radio/Television } \\
\hline Yes & $118(29.9)$ \\
\hline No & $276(70.1)$ \\
\hline \multicolumn{2}{|l|}{$\begin{array}{l}\text { Decision making power on place of delivery } \\
\text { delivery place }(n=394)\end{array}$} \\
\hline Self & $99(25.1)$ \\
\hline Husband & $116(29.4)$ \\
\hline My husband and me & $111(28.2)$ \\
\hline My relatives & $48(12.2)$ \\
\hline My husband relatives & $14(3.6)$ \\
\hline Others & $6(1.3)$ \\
\hline
\end{tabular}

*ETB ( Ethiopian birr), \$ 1 USD is equivalent to 18.5 ETB.

pregnancy took place before the age of 20 years. With regard to the recent pregnancy, about 27 (6.9\%) of mother were become pregnant at the age of less than 20 years, 241 (61.2\%) mothers were become pregnant between the age of 20 and 34 years and the rest 126 (32\%) at the age of 35 years and above. Most of them 332 (84.3\%) got ANC (antenatal) services during the last pregnancy, out of these 52 (13.2\%) were attended only once. Of all in- terviewed mothers, 50 (12.7\%) mothers become pregnant for the first time. Majority of respondents 195 (49.5\%) gave 5 and above births.

Out of the total respondents, only 62 (15.7\%) mothers gave birth at health institution. Of theses, 45 (11.4\%) gave birth at health center, $10(2.5 \%)$ at hospital and the rest $7(1.8 \%)$ at health post.

Majority of the respondents 332 (84.3\%) were delivered in home without skilled professionals. Among those who gave birth at home, 81 (20.6\%) were assisted by their husband, $73(18.5 \%)$ by their relatives, 53 (13.5\%) by their mother-in-law, 50 (12.7\%) by elderly mothers, $38(9.6 \%)$ by health extension workers, 21 (5.3\%) by Father-in-law, 13 (3.3\%) without any assistance and $3(0.3 \%)$ by traditional birth attendants (TBAs). Out of three hundred twenty one Mothers who knew the benefits of institutional delivery, 176 mothers got information from health workers, 259 mothers from health extension workers and 23 mothers from mass media (Table 2).

\subsection{Reasons for Institutional Delivery Service Utilization}

Reasons given for institutional delivery as mentioned by mother includes, 36\% mother were reported that they were informed to deliver at health institutional, 29\% need better service, $27 \%$ due to provider accountability and $3 \%$ of mothers reported due to the availability of health institutions in the nearby (Figure 1).

\subsection{Reasons for Not Utilizing Institutional Delivery Services}

The reasons for not utilizing the institutional delivery services as mentioned by mothers were; $26 \%$ mothers were due to too far distance, $15 \%$ of mother were due to short labor time, $14 \%$ of mothers were reported health providers do not understand mothers pain and were not

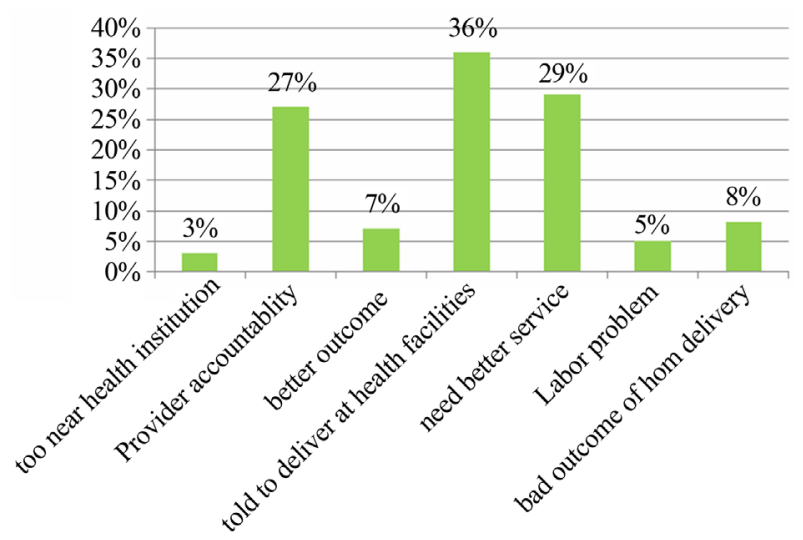

Figure 1. Reasons for institutional delivery among mothers in Banja District, North West Ethiopia, October, 20013. 
Table 2. Maternal factors of respondents $(\mathrm{N}=394)$ in Banja District, North West Ethiopia, October, 2013.

\begin{tabular}{|c|c|}
\hline Variables & $\mathbf{N}(\%)$ \\
\hline \multicolumn{2}{|l|}{ Age at last pregnancy } \\
\hline$<20$ & $27(6.9)$ \\
\hline $20-34$ & $241(61.2)$ \\
\hline $35+$ & $126(32)$ \\
\hline \multicolumn{2}{|l|}{ ANC visit during last pregnancy } \\
\hline Yes & 332 (84.3) \\
\hline No & $62(15.7)$ \\
\hline \multicolumn{2}{|c|}{ Number ANC visit during last pregnancy $(\mathrm{N}=332)$} \\
\hline Only one & $52(13.2)$ \\
\hline Two to three & $196(49.7)$ \\
\hline Four and above & $84(21.3)$ \\
\hline \multicolumn{2}{|l|}{ Birth order } \\
\hline 1 & $47(11.9)$ \\
\hline $2-4$ & $152(38.6)$ \\
\hline $5+$ & $195(49.5)$ \\
\hline \multicolumn{2}{|c|}{ Experience of Institutional delivery in the past } \\
\hline Yes & $40(10.2)$ \\
\hline No & $354(89.8)$ \\
\hline \multicolumn{2}{|l|}{ Place of last delivery } \\
\hline Health Institution & $62(15.7)$ \\
\hline Home & $332(84.3)$ \\
\hline \multicolumn{2}{|c|}{ Type of health institutional delivery } \\
\hline Hospital & $10(2.5)$ \\
\hline Health center & $45(11.4)$ \\
\hline Health post & $7(1.8)$ \\
\hline \multicolumn{2}{|l|}{ Category of Health care provider } \\
\hline Physician & $10(2.5)$ \\
\hline Health officer /Nurse/midwife & $45(11.4)$ \\
\hline Health extension worker & $7(1.8)$ \\
\hline \multicolumn{2}{|c|}{ Category of health care provider at home $(n=332)$} \\
\hline Traditional birth attendant & $3(0.8)$ \\
\hline Elderly mothers & $50(12.7)$ \\
\hline Relatives & $73(18.5)$ \\
\hline Health extension workers & $38(9.6)$ \\
\hline Husband & $81(20.6)$ \\
\hline Mother-in-law & $53(13.5$ \\
\hline Father-in-law & $21(5.3)$ \\
\hline No one/Myself & $13(3.3)$ \\
\hline
\end{tabular}

culturally sensitive, $8 \%$ of mothers were due to cultural prohibition and $7 \%$ of mothers were mentioned that their husband were not willing to attend institutional delivery services (Figure 2).

\subsection{Reasons for Home Delivery}

Reasons mentioned by mother for preference of home delivery includes, $41 \%$ mother reported that labor was smooth and short, $15 \%$ reported that they feel more comfort, $11 \%$ mothers reported that home delivery fulfills cultural needs and 9\% mothers were needing the support of their relatives at home (Figure 3).

\subsection{Factors Associated with Institutional Delivery Service Utilization}

The effects of different independent variables were tested for institutional delivery service utilization using logistic

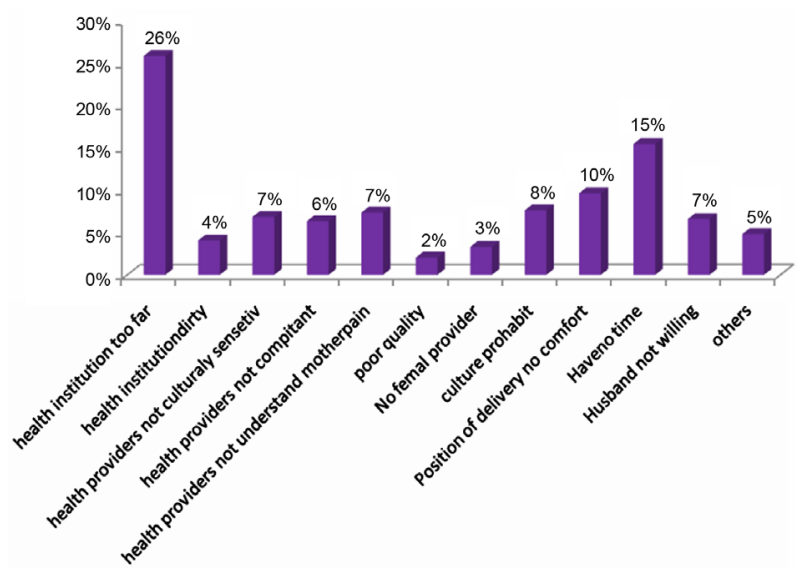

Figure 2. Reasons for not institutional delivery among mothers in Banja District, North West Ethiopia, October, 20013.

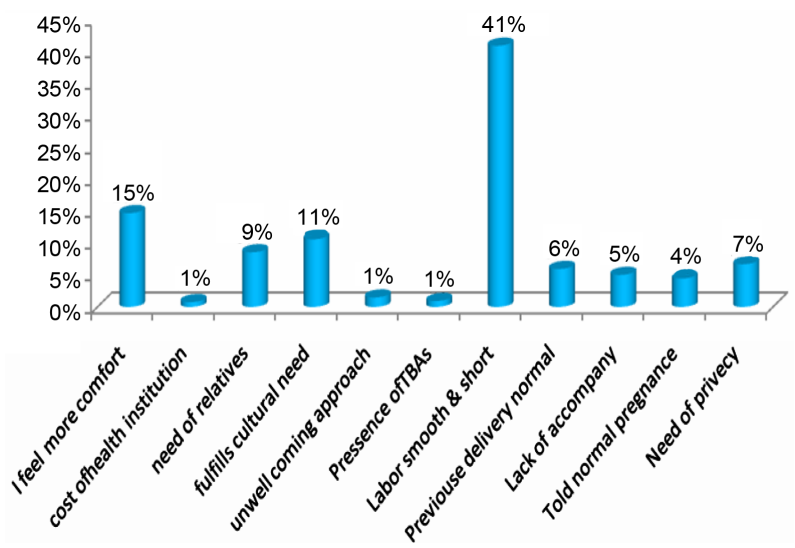

Figure 3. Reasons for home delivery among mothers in Banja District, North West Ethiopia, October, 2013.

regression analysis. Age of mothers, educational status of mothers and families, mothers' knowledge and previous experiences of institutional delivery service in the past were significantly associated with institutional delivery service utilization. Mothers who were in the age group of 15 - 24 years were nearly 3 times more likely to give birth at health institution (AOR $=2.76,95 \% \mathrm{CI}=1.02$, 7.49) than age group of 35 years and above. Mothers who attended secondary and above education were nearly 7 times to give birth at health institutions than mothers who were unable to read and write (AOR $=6.68,95 \%$ CI $=1.40,31.98)$. Mothers from educated family were 2 times more likely to give birth at health institution than less educated family members (AOR $=2.42,95 \%$ CI 1.13, 5.17). Mothers who had experience of giving birth at health institution in the past were about 16 times more likely to deliver in health institutions than mothers who did not have this experience $(\mathrm{AOR}=15.65,95 \% \mathrm{CI}=$ $6.48,37.79)$. Mothers who had enough knowledge on danger signs of labor were about 3 times more likely to institutional deliver than mothers who had not knowledge $(\mathrm{AOR}=2.51,95 \% \mathrm{CI}=0.1 .003,6.263)$ (Table 3$)$. 
Table 3. Factors associated with Institutional delivery service utilization among mothers in Banja District, North West Ethiopia, October, 2013.

\begin{tabular}{|c|c|c|c|c|}
\hline \multirow{2}{*}{ Variables } & \multicolumn{2}{|c|}{ Institutional delivery service utilization } & \multirow{2}{*}{ COR 95\% CI } & \multirow{2}{*}{ AOR 95\% CI } \\
\hline & Yes & No & & \\
\hline \multicolumn{5}{|l|}{ Age of mother's } \\
\hline $15-24$ & 20 & 49 & $2.16(1.07,4.38)$ & $2.76(1.02,7.49)$ \\
\hline $25-34$ & 22 & 177 & $0.66(0.34,1.26)$ & $0.68(0.30,1.57)$ \\
\hline$>=35$ & 20 & 106 & 1 & 1 \\
\hline \multicolumn{5}{|l|}{ Mother’s education } \\
\hline Unable to read and Write & 37 & 275 & 1 & $\begin{array}{c}1 \\
0.67(0.17 .255)\end{array}$ \\
\hline Able to read \& write & 4 & 26 & $1.14(0.38,3.46)$ & $0.67(0.17,2.55)$ \\
\hline Elementary $(1$ - 8) & 14 & 26 & $4.00(1.92,8.34)$ & $\begin{array}{l}2.47(0.88,6.98) \\
6.98(1-403198)\end{array}$ \\
\hline Secondary \& above & 7 & 5 & $10.40(3.14,34.47)$ & $6.68(1.40,31.98)$ \\
\hline \multicolumn{5}{|l|}{ Educated Family members } \\
\hline Half \& more & 36 & 103 & $3.08(1.77,5.37)$ & $2.42(1.13,5.17)$ \\
\hline Less than half & 26 & 229 & 1 & 1 \\
\hline \multicolumn{5}{|l|}{ Radio/television } \\
\hline Yes & 29 & 89 & $2.40(1.38,4.18)$ & $1.74(.83,3.64)$ \\
\hline No & 33 & 243 & 1 & 1 \\
\hline \multicolumn{5}{|l|}{ Mothers occupation } \\
\hline House wife & 53 & 310 & 1 & 1 \\
\hline Others & 9 & 22 & $2.39(1.045,5.479)$ & $2.60(0.77,8.80)$ \\
\hline \multicolumn{5}{|c|}{ Institutional delivery in the past } \\
\hline Yes & 25 & 15 & $14.28(6.92,29.48)$ & $15.65(6.48,37.79)$ \\
\hline No & 37 & 317 & 1 & 1 \\
\hline \multicolumn{5}{|l|}{ Knowledge on danger signs } \\
\hline Knowledgeable & 54 & 188 & $5.17(2.38,11.21)$ & $2.51(1.003,6.263)$ \\
\hline Not Knowledgeable & 8 & 144 & 1 & 1 \\
\hline \multicolumn{5}{|l|}{ Decision making power } \\
\hline Myself & 16 & 83 & 1 & 1 \\
\hline Husband & 7 & 109 & $0.33(0.13,0.85)$ & $0.47(0.15,1.47)$ \\
\hline Both & 31 & 80 & $2.01(1.02,3.96)$ & $2.34(0.98,5.60)$ \\
\hline Others & 8 & 60 & $0.69(0.28,1.72)$ & $0.67(0.22,2.10)$ \\
\hline
\end{tabular}

\section{DISCUSSION}

This community based study has attempted to identify the magnitude and factors associated with institutional delivery service utilization among mothers who gave birth in the last two years in Banja District, Ethiopia. The study showed that the magnitude of institutional delivery service utilization was $15.7 \%$ in the district. The majority of mothers (84.3\%) gave birth at home. This finding is nearly in line with other studies conducted in Ethiopia, Ethiopian demographic and health survey of 2011, 10.2\% in Amhara region [7], 13.5\% in North Gondar [9], 12.1 in Sekela district [10], 16\% in Arsi zone [11]. All of those studies reported that still large numbers of mothers are delivered at home under the care of untrained or unskilled birth attendants.

This study revealed that age of mothers, educational status of mothers and families, mothers' knowledge and previous experiences of institutional delivery service in the past were significantly associated with institutional delivery service utilization.

Mothers' age had significant association with institu- tional service utilization. Use of institutional delivery was significantly associated with mothers the younger the age $(15$ - 24) were about three times more likely to give birth in health institution than the 35 years and above (AOR $=2.76,95 \%$ CI 1.02, 7.49). This finding was consistent with the study done in Sekela district and Munisa district in Ethiopia [10,12]. The possible explanation is which may face complication and this is most likely their first birth, which demands health institution delivery. Additionally, younger mothers were more likely educated and better access to information than older mothers.

Educational status of mothers had also significant association with institutional service utilization. Mothers with secondary and above education level were about 7 times more likely to utilize institutional delivery service than unable to read and write $(\mathrm{AOR}=6.68,95 \% \mathrm{CI}=$ $1.40,31.98)$. This finding is also nearly consistent with other studies done in Ethiopia, Sekela District, North Gonder, Munisa, Arsi [10-12]. This might be because, when mothers are educated, they might have the power to make their own decision in matters related to their 
place of delivery. Education enables mothers to communicate and understand with any information concerning their health and perceive danger signs easily.

Mothers from educated families were two times more likely to utilize institutional delivery service than families $\mathrm{AOR}=2.42,95 \% \mathrm{CI}=1.13,5.17$ ) than mothers from less educated families. The possible reason might be more educated families in the house hold might access with different information and might help in discussing and sharing information for the mother about the benefits of institutional delivery.

Regarding previous experience, mothers who had experience of giving birth at health institution were about16 times more likely to give birth at health institution than those who did not have experience (AOR = 15.65, 95\% CI $=6.48$, 37.79). The possible explanation could be that mothers who had the history of institutional delivery have practical experience about the life treating conditions than those who did not. This experience could motivate the mother to give birth at health institution.

Mothers who had knowledge on danger signs of labor were about 3 times more likely to institutional deliver than mothers who had not knowledge $(\mathrm{AOR}=2.51,95 \%$ CI $=0.1003,6.263)$. A study done Sekela District and Arsi zone were also reported that there was statistically significant association with institutional delivery service utilization .The possible reason might be when they have better knowledge on danger signs of labor can perceive life treating conditions which in turn alerts them to decide where to deliver

\section{CONCLUSIONS}

This study revealed that the proportion of women who gave birth in health institution in the district was very low (15.7\%). Still large proportion of women gave birth at home without untrained or skilled attendant. Therefore, policy makers and health planners need to recognize the determinants of maternal service use like education of mothers and family, age of the mother, past experience of institutional delivery and knowledge on danger signs of labor. More efforts are required to educate women and families' focus antenatal care follow up that provides opportunity to inform that pregnancy and giving birth is risk at any time and age. Strengthening health education with experience sharing on danger signs and the benefits of institutional delivery is very important.

Programmers and other stockholders should work in creating awareness of the community on importance of institutional delivery by discussing danger signs of pregnancy or labor, which are risk at any time and at any age.

\section{ACKNOWLEDGEMENTS}

We would like to thank GAMBY College of Medical sciences and
Banja District Health office. We are also grateful for the cooperation of the study participants, data collectors and supervisors.

\section{REFERENCES}

[1] International Information Support Center. Mother and child health.

http://www.asksource.info/res library/mother.htm

[2] United Nations Children's Fund (UNICEF) (2008) Progress for children: A report card on maternal mortality. http://www.unicef.org/childsurvival/files/Progress_for_C hildren-No._7_Lo-Res_082008.pdf

[3] WHO, UNICEF, UNFPA and The World Bank Estimate Trends in maternal mortality: 1990 to 2010.

http://www.unfpa.org/webdav/site/global/shared/docume nts/publications/2012/Trends_in_maternal_mortality_A41 .pdf

[4] WHO (2013) Millennium development goal 5: Improve maternal health.

http://www.who.int/mediacentre/factsheets/fs290/en/

[5] United Nations (2008) Millennium development goals report. New York, 24-25.

[6] Central Statistical Agency [Ethiopia] and ORC Macro (2006) Ethiopia demographic and health survey (EDHS) 2005. Central Statistical Agency and ORC Macro, Addis Ababa, Ethiopia and Calverton, Maryland.

[7] Central Statistical Agency [Ethiopia] and ICF International (2012) Ethiopia Demographic and health survey (EHHS) 2011. Central Statistical Agency and ICF International, Addis Ababa, Ethiopia and Calverton, Maryland.

[8] Health Management Information System Report of Banja District Health Office for Year 2012/13. (Unpublished Report for Banja District Health Office).

[9] Nigussie, M., Haile, M.D. and Mitike, G. (2004) Assessment of safe delivery service utilization among mothers of childbearing age in north Gondar Zone, North West Ethiopia. Ethiopian journal of Health Development, 18, 145-152.

[10] Alemayehu, T., Mazengia, F. and Meseret, S. (2012) Institutional delivery service utilization and associated factors among mothers who gave birth in the last 12 months in Sekela District, North West of Ethiopia. BMC Pregnancy and Childbirth, 12, 74. http://dx.doi.org/10.1186/1471-2393-12-74

[11] Abera, M., Gmariam, A. and Belachew, T. (2011) Predictors of safe delivery service utilization in Arsi zone, south-east Ethiopia. Ethiop Journal of Health Sciences, 21, 101-113.

[12] Amano, A., Gebeyehu, A. and Birhanu, Z. (2012) Institutional delivery service utilization in Munisa Woreda, South East Ethiopia: A community based cross sectional study. BMC Pregnancy and Childbirth, 12, 105. http://dx.doi.org/10.1186/1471-2393-12-105 